\title{
Technologies for Upgrading Light Water Reactor Outlet Temperature
}

\section{HT2013}

The INL is a

U.S. Department of Energy

National Laboratory

operated by

Battelle Energy Alliance

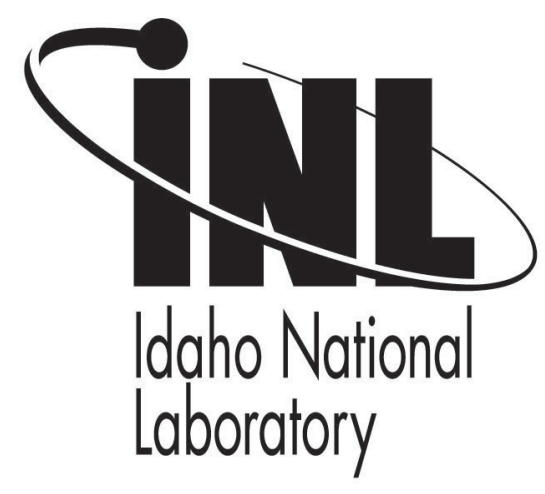

\section{Daniel S. Wendt \\ Piyush Sabharwall Vivek Utgikar}

\section{July 2013}

This is a preprint of a paper intended for publication in a journal or proceedings. Since changes may be made before publication, this preprint should not be cited or reproduced without permission of the author. This document was prepared as an account of work sponsored by an agency of the United States Government. Neither the United States Government nor any agency thereof, or any of their employees, makes any warranty, expressed or implied, or assumes any legal liability or responsibility for any third party's use, or the results of such use, of any information, apparatus, product or process disclosed in this report, or represents that its use by such third party would not infringe privately owned rights. The views expressed in this paper are not necessarily those of the United States Government or the sponsoring agency. 


\section{TECHNOLOGIES FOR UPGRADING LIGHT WATER REACTOR OUTLET TEMPERATURE}

\author{
Daniel S. Wendt \\ Idaho National Laboratory \\ Idaho Falls, ID, USA
}

\author{
Piyush Sabharwall \\ Idaho National Laboratory \\ Idaho Falls, ID, USA
}

\author{
Vivek Utgikar \\ University of Idaho \\ Moscow, ID, USA
}

\begin{abstract}
Nuclear energy could potentially be utilized in hybrid energy systems to produce synthetic fuels and feedstocks from indigenous carbon sources such as coal and biomass. First generation nuclear hybrid energy system (NHES) technology will most likely be based on conventional light water reactors (LWRs). However, these LWRs provide thermal energy at temperatures of approximately $300^{\circ} \mathrm{C}$, while the desired temperatures for many chemical processes are much higher. In order to realize the benefits of nuclear hybrid energy systems with the current LWR reactor fleets, selection and development of a complimentary temperature upgrading technology is necessary. This paper provides an initial assessment of technologies that may be well suited toward LWR outlet temperature upgrading for powering elevated temperature industrial and chemical processes during periods of off-peak power demand.

Chemical heat transformers (CHTs) are a technology with the potential to meet LWR temperature upgrading requirements for NHESs. CHTs utilize chemical heat of reaction to change the temperature at which selected heat sources supply or consume thermal energy. CHTs could directly utilize LWR heat output without intermediate mechanical or electrical power conversion operations and the associated thermodynamic losses. CHT thermal characteristics are determined by selection of the chemical working pair and operating conditions. This paper discusses the chemical working pairs applicable to LWR outlet temperature upgrading and the CHT operating conditions required for providing process heat in NHES applications.
\end{abstract}

\section{INTRODUCTION}

Nuclear energy is an emissions-free alternative to fossil fuels for electric power generation and industrial process heat. In combination with carbon conversion processes, nuclear energy could be used to produce synthetic fuels and feedstocks from indigenous carbon sources such as coal and biomass. These nuclear hybrid energy systems (NHES), which combine nuclear energy with renewable and fossil resources, have significant potential to contribute to national energy security. To be deployed, NHESs need to overcome significant technical, economic, and political challenges. The next generation reactor systems that can provide the necessary high temperatures for process applications are faced with regulatory uncertainties, and the first generation NHES technology will most likely be based on conventional light water reactors (LWRs). However, these LWRs provide thermal energy at temperatures of about $300^{\circ} \mathrm{C}$, while the desired temperatures for many chemical processes are much higher as indicated in Figure 1 -for example, pyrolysis and hydrotreatment/hydrocracking $\left(500^{\circ} \mathrm{C}\right)$, or gasification or reforming (up to $800^{\circ} \mathrm{C}$ ). In order to realize the benefits of nuclear hybrid energy systems with the current LWR reactor fleets, selection and development of a complimentary temperature upgrading technology is necessary. This paper provides an initial assessment of temperature upgrading technologies that may be well suited toward LWR temperature upgrading, and identifies the technology that will be researched for this application by the Idaho National Laboratory and the University of Idaho.

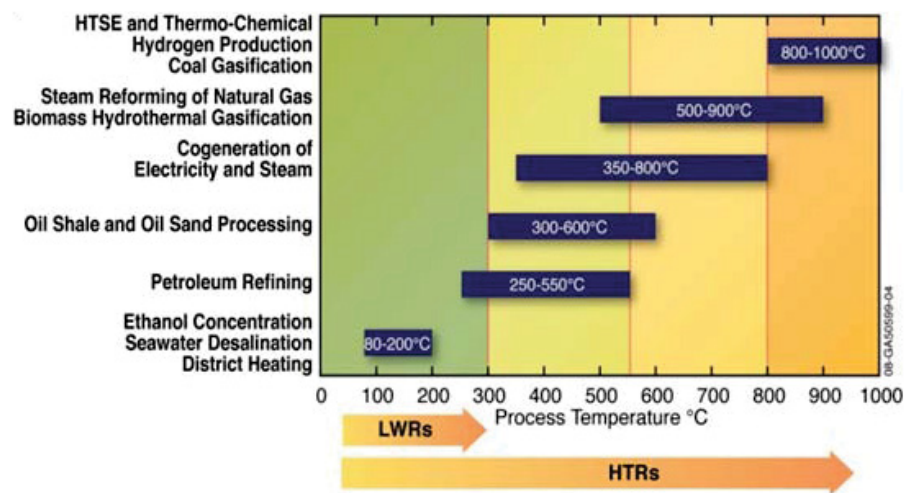

Figure 1: Process heat applications of nuclear reactors (Park, Patterson, Maio, \& Sabharwall, 2009) 


\section{NOMENCLATURE}

$\mathrm{P}$ pressure

$\mathrm{T}$ temperature

subscripts

$\mathrm{H}$ high (temperature or pressure)

L low (temperature or pressure)

$\mathrm{M}$ intermediate (temperature)

\section{INDUSTRY NEEDS}

Nuclear power provides a reliable and emissions free base load power source. Nuclear power plants are expensive to permit, construct, and operate and since they do not operate in a load following mode, are most economical to operate at full output so as to maximize the net power generation and power sales revenues. The nuclear power plant excess power generation capacity during times of low electrical power demand could potentially be either stored or used in a nuclear hybrid energy system (NHES) to produce products other than electricity that could be sold at premium pricing while simultaneously diversifying the national energy supply.

Such hybrid energy systems would convert the excess nuclear reactor heat to another energy form that could be readily stored and then recovered during times of elevated electrical power demand. Candidate energy storage methods include mechanical (compressed fluids, pumped storage), thermal (sensible or latent heat), or chemical energy storage technologies. Alternatively, the excess nuclear power could be utilized for upgrading raw materials to higher value products via chemical processes. A product of considerable interest is liquid transportation fuel synthesized from coal, natural gas, or biomass carbon sources.

Although high temperature nuclear reactor technology exists, regulatory and political uncertainty may prevent or result in long delays before high temperature reactors are deployed. Current LWRs operate with secondary loop outlet temperatures of approximately $300^{\circ} \mathrm{C}$. Thermochemical conversion of biomass requires temperatures in the range of $700-850^{\circ} \mathrm{C}$ and pressures of 1-3 MPa for syngas production (Bain, 2004). In order for the thermal energy for thermochemical biofuels production/conversion processes to be provided by LWRs, temperature upgrading of the LWR secondary loop heat transfer is a technology that should be investigated.

Biomass gasification involves partial oxidation of the biofuel carbon source and reaction with steam to form a synthesis gas, or syngas, stream of $\mathrm{CO}$ and $\mathrm{H}_{2}\left(\right.$ and $\left.\mathrm{CO}_{2}\right)$, with the $\mathrm{CO} / \mathrm{H}_{2}$ ratio typically in the range of 0.5 to 2 (Bain, 2004). The $\mathrm{CO} / \mathrm{H}_{2}$ ratio is determined by the quantity of steam used in the conditioning step. Gasifier types include updraft, downdraft, fluid-bed, circulating fluid-bed, and entrained flow gasifiers. As indicated in Table 1, syngas produced from biomass gasification could be utilized to produce any number of chemical products including hydrogen, alcohols, olefins, oxochemicals, ammonia, synthetic natural gas (SNG), as well as Fischer-Tropsch gasoline and/or diesel fuel.

Implementation of NHES systems to utilize nuclear power for synthesis of biofuels would result in numerous economic, societal, and national security benefits. First, it is expected that thermochemical biofuels synthesis would result in decreased carbon emissions relative to using petroleum resources for transportation fuels; a life cycle analysis to be performed at a later stage will quantify the carbon emissions from each of these transportation fuel production methods. In addition to decreasing carbon emissions, large scale deployment of a technology allowing thermochemical conversion of biomass into liquid transportation fuels using nuclear energy would decrease dependence on foreign oil sources and assist in stabilizing transportation fuel and energy prices.

Table 1. Products that can be derived/synthesized from syngas $\left(\mathrm{CO}+\mathrm{H}_{2}\right)$ precursor (Bain, 2004)

\begin{tabular}{|c|c|}
\hline product & route \\
\hline waxes, diesel & $\begin{array}{l}\text { Fischer-Tropsch synthesis (using Fe, Co, } \\
\text { Ru catalysts) }\end{array}$ \\
\hline olefins, gasoline & $\begin{array}{l}\text { Fischer-Tropsch synthesis (using Fe, Co, } \\
\text { Ru catalysts) }\end{array}$ \\
\hline mixed alcohols & $\begin{array}{l}\text { Alkali-doped } \mathrm{ZnO} / \mathrm{Cr}_{2} \mathrm{O}_{3} ; \mathrm{Cu} / \mathrm{ZnO} ; \\
\mathrm{Cu} / \mathrm{ZnO} / \mathrm{Al}_{2} \mathrm{O}_{3} ; \mathrm{CuO} / \mathrm{CoO} / \mathrm{Al}_{2} \mathrm{O}_{3} ; \mathrm{MoS}_{2}\end{array}$ \\
\hline isobutane & isosynthesis $\left(\mathrm{ThO}_{2}\right.$ or $\left.\mathrm{ZrO}_{2}\right)$ \\
\hline hydrogen & $\mathrm{H}_{2} \mathrm{O}$ water-gas-purify \\
\hline ammonia & $\begin{array}{l}\text { hydrogen production followed by reaction } \\
\text { with } \mathrm{N}_{2} \text { over } \mathrm{Fe} / \mathrm{FeO}\left(\mathrm{K}_{2} \mathrm{O}, \mathrm{Al}_{2} \mathrm{O}_{3}, \mathrm{CaO}\right) \\
\text { catalyst }\end{array}$ \\
\hline $\begin{array}{l}\text { aldehydes, } \\
\text { alcohols }\end{array}$ & $\begin{array}{l}\text { oxosynthesis: } \mathrm{HCo}(\mathrm{CO})_{4} \\
\mathrm{HCo}(\mathrm{CO})_{3} \mathrm{P}\left(\mathrm{Bu}_{3}\right) ; \mathrm{Rh}(\mathrm{CO})\left(\mathrm{PPh}_{3}\right)_{3}\end{array}$ \\
\hline ethanol & synthesis catalyzed by $\mathrm{Co}, \mathrm{Rh}$ \\
\hline methanol & synthesis catalyzed by $\mathrm{Cu} / \mathrm{ZnO}$ \\
\hline olefins, gasoline & $\begin{array}{l}\text { methanol production followed by MTO } \\
\text { and MTG processes, zeolite catalysis }\end{array}$ \\
\hline MTBE & $\begin{array}{l}\text { methanol production followed by } \\
\text { isobutylene, acidic ion exchange }\end{array}$ \\
\hline DME & $\begin{array}{l}\text { methanol production followed by } \mathrm{Al}_{2} \mathrm{O}_{3} \\
\text { catalysis }\end{array}$ \\
\hline acetic acid & $\begin{array}{l}\text { methanol production followed by } \\
\text { carbonylation reaction catalyzed by } \mathrm{Co} \text {, } \\
\mathrm{Rh}, \mathrm{Ni}\end{array}$ \\
\hline formaldehyde & $\begin{array}{l}\text { methanol production followed by } \mathrm{Ag} \\
\text { catalysis }\end{array}$ \\
\hline
\end{tabular}

\section{TEMPERATURE UPGRADING TECHNOLOGIES}

The following section provides an overview of temperature upgrading technologies, general operating principles, and relevant process conditions. The temperature upgrading technologies considered include mechanical heat pumps, vapor absorption heat pumps, chemical heat pumps, as well as solid state heat pumps.

\section{A. Mechanical Heat Pumps}

\section{A.1. Vapor Compression (reverse Rankine cycle)}

Vapor compression heat pumps utilize the Rankine cycle operating in reverse. Low temperature heat is input to an 
evaporator, where a working fluid in the liquid phase is vaporized. Mechanical power is used to compress the vapor phase working fluid, increasing the temperature of the vapor to produce a superheated vapor. The superheated vapor is then cooled and condensed, releasing heat at a temperature greater than that input to the evaporator. The liquid then flows through a valve where its pressure is reduced prior to reentering the evaporator. The heat released from the cycle in the condenser may be used for the desired application.

Various working fluids may be utilized in the vapor compression heat pump, depending on the heat source and sink temperatures and desired process characteristics. Supercritical $\mathrm{CO}_{2}$ heat pump cycles may achieve output temperatures of up to $150^{\circ} \mathrm{C}$ using waste heat input (Thermea Energiesysteme, 2008).

Open or semi-open systems utilizing mechanical vapor recompression (MVR) and condensation of vapor from industrial processes work with heat-source temperatures from $70-80^{\circ} \mathrm{C}$ and deliver heat between 110 and $150^{\circ} \mathrm{C}$, in some cases up to $200^{\circ} \mathrm{C}$ (Heat Pump Centre, 2007).

\section{A.2. Gas Cycle (reverse Brayton cycle)}

The reverse Brayton cycle may also be used for heat pumping applications. In this cycle, the working fluid remains in the gas phase, resulting in use of gas-to-gas heat exchangers and large volumetric flow rates. The absence of working fluid phase changes results in non-isothermal heat exchange operations, which may decrease process efficiency, depending on the application. Efficiencies similar to those of conventional vapor compression cycles can be obtained through selection of cycle operating parameters such that the expansion process occurs in the vicinity of the working fluid critical point (Angelino and Invernizzi, 1995).

Known Brayton cycle industrial heat pump applications include low temperature drying $\left(<150^{\circ} \mathrm{F}\right)$ and solvent recovery applications (Mills and Chappell, 1985; and Heat Pump Centre, 2007).

\section{A.3 Stirling cycle}

Heat pumps based on the Stirling cycle are not widely utilized. Analysis of the cycle indicate several potential advantages, such as high efficiency, with a coefficient of performance (COP) approaching that of an equivalent Carnot cycle. Stirling cycles can utilize noncondensible working fluids, such as hydrogen or helium that are not limited by thermal instability (Mills and Chappell, 1985). However, no known high temperature upgrading applications exist at the present time.

\section{B. Vapor Absorption Heat Pumps}

Absorption heat pumps are driven by thermal rather than mechanical or electrical power sources. Sorption heat pumps use the heat of (de) sorption of a medium to transfer heat between different temperature levels. Absorption heat pumps may utilize multiple stages to increase system efficiency. Ammonia-water and LiBr-water are the two most common absorption heat pump working fluids. Absorption heat pumps typically have lower efficiency than mechanical heat pumps, but have advantageous properties, such as few moving parts and no mechanical or electrical requirements (aside from instrumentation and valving), that make them favorable in certain applications.

Current LiBr-water absorption heat pump systems achieve an output temperature of $100^{\circ} \mathrm{C}$ and a temperature lift of $65^{\circ} \mathrm{C}$ (Heat Pump Centre, 2007). Typical LiBr heat transformer temperatures are limited due to corrosion effects. However, a specialized LiBr-water heat transformer configuration using corrosion resistant graphite has been proposed for operation at temperatures up to $230^{\circ} \mathrm{C}$ (Le Goff et al, 1993). The newest generation of advanced absorption heat pumps are capable of output temperatures up to $260^{\circ} \mathrm{C}$ (Heat Pump Centre, 2007).

\section{Chemical Heat Pumps}

Chemical heat pumps (CHPs) are systems that use reversible chemical reactions to change the temperature level of the thermal energy stored by the chemicals. The energy storage step involves an endothermic reaction, and the stored energy is released during the reverse exothermic reaction. Chemical heat pumps can be configured to operate in heat amplifying or temperature amplifying mode. The reaction conditions (pressure, compositions) are manipulated such that the energy release occurs with amplified heat duty or at a higher temperature. CHP -based energy storage is characterized by high capacity, long term storage and low heat loss.

CHPs may be categorized as sorption-based or chemical reaction-based depending on the physical characteristics of the reactants (also referred to as the working pair). Chemical reaction-based CHPs have the greatest potential for high-lift temperature amplification applications. Chemical heat pumps that operate in temperature amplifying mode are often referred to as chemical heat transformers (CHTs).

Chemical heat transformers can utilize heat sources such as LWR heat directly without requiring conversion of the energy to mechanical and or electrical power. Direct utilization of the LWR secondary loop heat stream eliminates thermodynamic losses associated with conversion to mechanical and electrical power (some thermodynamic losses will be associated with the primary to secondary loop heat exchange process). The primary source of inefficiency in chemical heat transformer operation is the batch operating mode that necessitates reactor heating and cooling between production and regeneration operations (with no temperature upgrading occurring during these steps). The efficiency of the CHT temperature amplification process can be increased by integrating heat utilization to include operations such as recuperation of residual heat at the end of the production phase for use in preheating the regeneration phase reactor.

CHTs offer a wider range of operating temperature and versatility in comparison with conventional vapor compression or (de) sorption heat pumps (Arjmand et al, 2012).

\section{Solid State Heat Pumps}

Solid state heat pumps use magnetic or thermoelectric effects to achieve thermal energy transport and conversion 
processes. Solid state heat pumps require electrical input to achieve temperature transformation. Theoretical analysis of magnetic heat pumps indicate that the process equipment involves few moving parts, cycle efficiencies could approach Carnot limits with heat transfer being the only inherent irreversibility, and the use of a solid working material eliminates compressors, turbines, and pressure containment problems (Mills and Chappell, 1985). Although numerous magnetic heat pump devices have been tested, maximum temperature lifts obtained are on the order of $50 \mathrm{~K}$ and the application of these devices appears to be best suited toward refrigeration and space heating and cooling applications.

\section{TECHNOLOGY REQUIREMENTS AND SELECTION FOR LWR TEMPERATURE UPGRADING}

The application of upgrading LWR outlet temperature for providing process heat for thermochemical synthesis of liquid transportation fuels from biomass has a number of specific technology requirements. A list of requirements is provided below:

- Ability to upgrade LWR outlet temperature to levels required for gasification operations $\left(700-850^{\circ} \mathrm{C}\right)$

- Ability to integrate with nuclear hybrid energy systems (tolerant of dynamic or transient operation)

- Economic viability, reliability, and operational safety

- Direct utilization of LWR heat: Technologies that require mechanical and/or electrical input as the primary energy source will require an additional power conversion operation that is expected to reduce net process efficiency. This requirement eliminates mechanical and solid state (magnetic, thermoelectric, thermoacoustic) heat pumps.

- Higher efficiency and better economics than the use of electrical Joule heating to obtain temperature upgrading

- NHES operation should provide increased revenues in comparison to entirely electric power generation. The value of chemical products produced using upgraded process heat must outweigh additional process equipment, operations, and maintenance costs in addition to lost/displaced electrical power sales revenues.

\section{TECHNOLOGY SELECTION}

Temperature upgrading via mechanical heat pumps is undesirable for LWR coupling due to the requirement that the LWR heat first be converted to mechanical or electrical power, introducing additional operations and thermodynamic losses into the temperature upgrading process. Based on the above selection criteria, chemical heat transformers have been chosen for further evaluation and analysis in the application of upgrading LWR outlet temperature for thermochemical synthesis of liquid transportation fuels. Future detailed analysis to be completed will include an efficiency analysis between CHT temperature amplification and a base case in which electrical resistance Joule heating is used to produce process heat at the specified temperature levels.
A limited number of chemical reaction-based chemical heat transformers have been tested experimentally. The chemical working pairs that have been tested under various experimental conditions for temperature upgrading applications include $\mathrm{Mg}(\mathrm{OH})_{2} / \mathrm{MgO}, \mathrm{Ca}(\mathrm{OH})_{2} / \mathrm{CaO}$, and $\mathrm{CaCO}_{3} / \mathrm{CaO}+$ $\mathrm{PbCO}_{3} / \mathrm{PbO}$ (Cot-Gores et al, 2012). The following list summarizes advantages and issues associated with each of the chemical reaction pairs.

\section{CaO Hydration/Dehydration:}

$\mathrm{CaO}(\mathrm{s})+\mathrm{H}_{2} \mathrm{O}(\mathrm{g}) \leftrightarrow \mathrm{Ca}(\mathrm{OH})_{2}(\mathrm{~s})$

- Advantages (Hasatani, 1992)

○ High thermal energy storage density (over $1250 \mathrm{~kJ} / \mathrm{kg}$ )

○ High output temperature $(773 \mathrm{~K}+)$

- High reaction rate

- Good reaction reversibility and durability

- No toxicity, good reactant corrosion resistance

- Abundant and low cost $\mathrm{CaO}$ resources

- Hydration/dehydration reaction permits use of evaporator/condenser for low temperature reactor (simple and low cost method of collecting, storing, and regenerating mobile phase; eliminates additional packed bed batch mode only reactor; simplified process control and operation; improved heat and mass transfer characteristics)

- Does not release any contaminating gases (Ogura, 1999)

- Issues (Hasatani, 1992)

- Pulverization of reactant resulting from multiple reaction cycles

- Carbonization of $\mathrm{CaO}$

○ Relatively high regeneration temperature $(573 \mathrm{~K}+)$

CaO Carbonation/Decarbonation:

$\mathrm{CaO}(\mathrm{s})+\mathrm{CO}_{2}$ (g) $\leftrightarrow \mathrm{CaCO}_{3}$ (s)

- Advantages

- $\mathrm{CO}_{2}$ storage as compressed gas; other carbonate (i.e. $\mathrm{MgCO}_{3}$ or $\mathrm{PbCO}_{3}$ ); or as adsorbed onto zeolite, activated carbon, or other adsorbent

○ Thermal energy storage in range of $773-1073 \mathrm{~K}$ (Kyaw, 1997)

- Reaction products free from toxicity and corrosiveness and raw materials are abundantly available

- $\mathrm{CaO}-\mathrm{CO}_{2}$ reversible reaction has no side reactions

- Issues

- $\mathrm{CaCO}_{3}$ dissociates at $1098 \mathrm{~K}$ under $101 \mathrm{kPa}$ of $\mathrm{CO}_{2}$ pressure

MgO Hydration/Dehydration:

$\mathrm{MgO}(\mathrm{s})+\mathrm{H}_{2} \mathrm{O}(\mathrm{g}) \leftrightarrow \mathrm{Mg}(\mathrm{OH})_{2}(\mathrm{~s})$

- Advantages

○ demonstrated performance in heat amplification and temperature amplification modes of operation

- Issues

○ practical operating regime constrained to low temperatures (define range) 
The $\mathrm{CaO}$ hydration/dehydration chemical heat transformer has characteristics that make it best suited for future detailed analysis of the high lift LWR temperature upgrading application. These characteristics include high output temperature potential, high reaction rate, high thermal energy storage density, good reaction reversibility and durability, abundant low cost reactant, low corrosion, and non-toxic reaction products.

\section{CHEMICAL HEAT TRANSFORMER WORKING PRINCIPLES}

A CHT unit consists of two reactors (or a reactor and an evaporator/condenser) with transport of a mobile phase taking place in a batch process; Two or more units each consisting of the high and low temperature reactors (or reactor and evaporator/condenser) must be implemented to achieve pseudosteady state operation (see Figure 2).

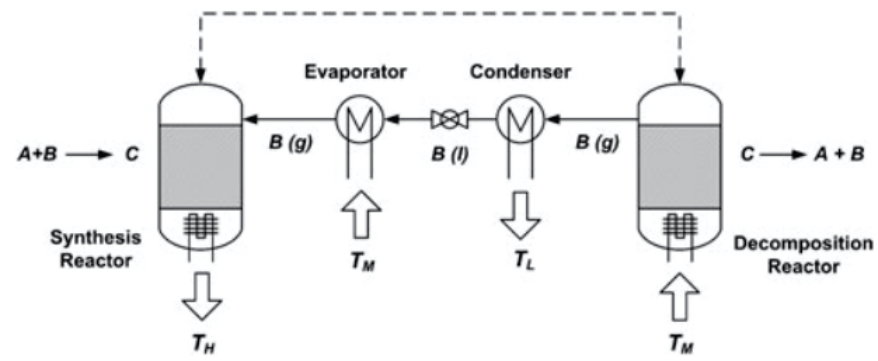

Figure 2. Schematic of a CHT operating in the temperaturelevel amplification mode (Arjmand et al, 2012)

The following discussion is based on a chemical heat transformer utilizing a steam evaporator/condenser and a high temperature $\mathrm{CaO}$ hydration/dehydration reactor. The general $\mathrm{P}-\mathrm{T}$ relationships for water vaporization and the $\mathrm{CaO}$ hydrationdehydration reaction are described by the equilibrium lines on the Clausius-Clapeyron diagram shown in Figure 3.

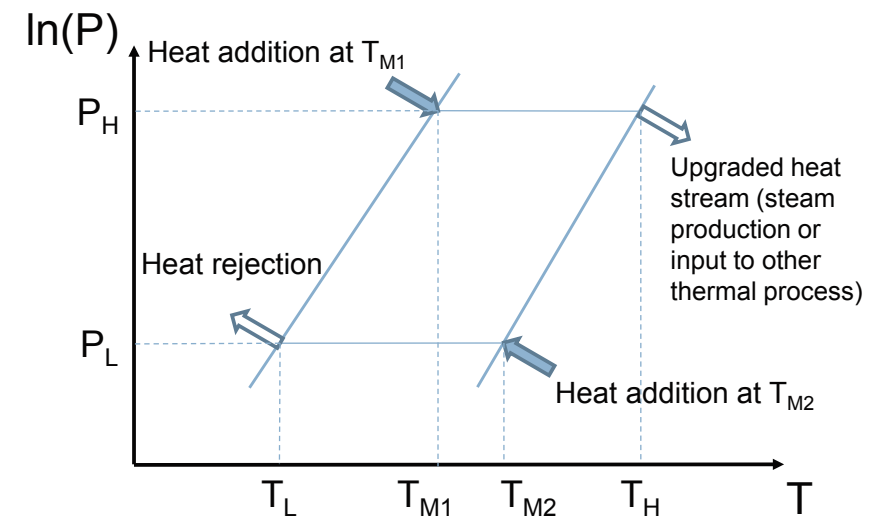

Figure 3. Clausius-Clapeyron diagram illustrating high and low temperature reaction equilibrium/operating lines (diagonal). The solid horizontal lines indicate the flow of steam between the condenser (lower temperature operating line) and the fixed bed reactor (higher temperature operating line).

\section{Synthesis/Production/Heat-Release Step}

The synthesis/production/heat-release step will be described from an initial condition in which the evaporator is charged with condensed water and the $\mathrm{CaO}$ reactor bed is in the regenerated (dehydrated) state. The synthesis/production/heatrelease step releases high temperature heat and is initiated when water in the evaporator is vaporized using an external heat source supplied at intermediate temperature $T_{M 1}$. A control valve on the evaporator outlet is kept closed as the evaporator temperature increases from $\mathrm{T}_{\mathrm{L}}$ to $\mathrm{T}_{\mathrm{M} 1}$, resulting in an increase in the evaporator pressure from $\mathrm{P}_{\mathrm{L}}$ to $\mathrm{P}_{\mathrm{H}}$ (the vapor pressure of the steam increases according to the saturated steam equilibrium T-P relation). When the evaporator temperature reaches $T_{M 1}$, a steam vapor pressure of $\mathrm{P}_{\mathrm{H}}$ exists, at which point the control valve is opened to allow steam at pressure $\mathrm{P}_{\mathrm{H}}$ to enter the $\mathrm{CaO}$ reactor.

The $\mathrm{CaO}$ reactor bed is at an initial temperature $\mathrm{T}_{\mathrm{M} 2}$ following regeneration of the reactant $\left(\mathrm{Ca}(\mathrm{OH})_{2}\right.$ dehydration). As steam flows into the reactor and diffuses throughout the $\mathrm{CaO}$ bed, exothermic $\mathrm{CaO}$ hydration reactions will begin to occur. Initially the heat of reaction from the exothermic hydration reactions will be utilized to increase the temperature of the reactor bed. During this bed warm-up period, no net heat will be exported from the reactor. As a consequence, the heat of reaction generated by the hydration reactions during the bed warm-up period cannot be utilized for temperature amplification activities, and is consequently a source of system inefficiency.

Once the heat generated by the exothermic hydration reactions has heated the reactor bed to the specified output temperature $\mathrm{T}_{\mathrm{H}}$, the heat produced by the hydration reactions can be utilized to supply heat to external processes at the upgraded temperature level. The temperature at which the exothermic $\mathrm{CaO}$ hydration reaction proceeds is determined by the steam pressure in the reactor. A steam pressure of $\mathrm{P}_{\mathrm{H}}$ must be maintained for the hydration reactions to proceed at temperature $\mathrm{T}_{\mathrm{H}}$. Therefore, the evaporator performance must be sufficient to generate steam at a rate equal to that at which the steam reacts with the $\mathrm{CaO}$ in the fixed bed reactor.

Energy from the exothermic hydration reaction will be released until the hydration reaction has reached completion or the steam supply is disrupted. An efficient reactor design will likely require a mechanism by which the generated heat can be transferred from the reactor bed, such as a cooling coil through which a heat transfer fluid is pumped.

\section{Regeneration/Decomposition Step}

Upon completion of the hydration reaction, the $\mathrm{CaO}$ reactor bed must be cooled to temperature $\mathrm{T}_{\mathrm{M} 2}$ for regeneration. The sensible heat rejected as the reactor bed is cooled from $T_{H}$ to $\mathrm{T}_{\mathrm{M} 2}$ may be utilized for providing evaporator duty or reactor bed preheating for a separate CHT unit, or for providing exportable process heat at $\mathrm{T}>\mathrm{T}_{\mathrm{M} 2}$.

In order for the regeneration operations to occur, the reactor bed pressure must be decreased to a pressure of $\mathrm{P}_{\mathrm{L}}$. The system pressure is reduced by condensing steam in the 
condenser at a temperature corresponding to the desired saturation pressure. Consequently, the condenser cooling duty must be provided at a temperature $T_{L}$ to reduce the system pressure to $\mathrm{P}_{\mathrm{L}}$. Heat at temperature $\mathrm{T}_{\mathrm{M} 2}$ is input to the $\mathrm{CaO}$ reactor bed to drive the endothermic dehydration reaction. The water vapor generated by the dehydration reactions flows to the condenser as a result of the pressure differential established as water vapor is condensed.

If the same heat source is to be used for operation of the evaporator and providing heat for reactor dehydration, then $\mathrm{T}_{\mathrm{M} 1}=\mathrm{T}_{\mathrm{M} 2}$, which effectively specifies $\mathrm{P}_{\mathrm{H}}$ and $\mathrm{P}_{\mathrm{L}}$ and the corresponding heat upgrade temperature $\mathrm{T}_{\mathrm{H}}$ and condenser temperature $\mathrm{T}_{\mathrm{L}}$.

\section{CONCLUSION}

There are several potential technologies that could likely achieve temperature amplification of the magnitude required for upgrading LWR outlet temperature for liquid transportation fuels synthesis. Chemical heat transformers and vapor absorption heat pumps are the technologies that are best suited for direct use of the thermal energy in the LWR secondary loop. The maximum operating temperature associated with vapor absorption heat pumps is limited to temperatures below what is required for driving the gasification reactions necessary to produce synthetic liquid transportation fuels from biomass. Chemical heat transformers therefore have a unique set of characteristics that make them an attractive option for the task of providing high-lift temperature upgrading of LWR outlet temperature. Of the reaction chemical heat transformers that have been investigated by the scientific community, the $\mathrm{Ca}(\mathrm{OH})_{2} / \mathrm{CaO}$ chemical heat transformer has characteristics that make it best suited for future detailed analysis of the high lift LWR temperature upgrading application. These characteristics include high output temperature potential, high reaction rate, high thermal energy storage density, good reaction reversibility and durability, abundant low cost reactant, low corrosion, and non-toxic reaction products.

\section{REFERENCES}

Ally, M. R., \& Rebello, W. J. (1985). Application of Reversible Chemical Reactions for Temperature Amplification. Proceedings from the Seventh National Industrial Energy Technology Conference, (pp. 489-494). Houston, TX.

Angelino, G. and Invernizzi, C. (1995). Prospects for realgas reversed Brayton cycle heat pumps. Int. J. Refrig. 18 (4) 272-280.

Arjmand, M., Liu, L., \& Neretnieks, I. (2012). Exergetic Efficiency of High-Temperature-Lift Chemical Heat Pump
(CHP) Based on $\mathrm{CaO} / \mathrm{CO}_{2}$ and $\mathrm{CaO} / \mathrm{H}_{2} \mathrm{O}$ Working Pairs. International Journal of Energy Research.

Bain, Richard L. (2004). An Introduction to Biomass Thermochemical Conversion. DOE/NASLUGC Biomass and Solar Energy Workshops.

Cot-Gores, J., Castell, A., \& Cabeza, L. F. (2012). Thermochemical Energy Storage and Conversion: A-State-ofthe-Art Review of the Experimental Research Under Practical Conditions. Renewable and Sustainable Energy Reviews, 16, 5207-5224.

Heat Pump Centre. (2007). Heat Pumps in Industry. Retrieved May 9, 2013, from Heat Pump Centre: http:/www.heatpumpcentre.org/en/aboutheatpumps/heatpumpsi nindustry/Sidor/default.aspx

Kyaw, K., Shibata, T., Watanabe, F., Matsuda, H, and Hasitani, M. (1997). Applicability of Zeolite for $\mathrm{CO}_{2}$ Storage in a $\mathrm{CaO}-\mathrm{CO}_{2}$ High Temperature Energy Storage System. Energy Convers. Mgmt. 38 (10) 1025-1033.

Le Goff, P., Le Goff, H., Soetrisnanto, A., \& Labidi, J. (1993). New techniques for upgrading industrial waste heat. Experimental Thermal and Fluid Science 7 (2) 132.

Mills, J. I., and Chappell, R. N. (1985). Advanced Mechanical Heat Pump Technologies for Industrial Applications. Proceedings from the Seventh National Industrial Energy Technology Conference, (pp. 471-478). Houston, TX.

Park, C., Patterson, M., Maio, V., \& Sabharwall, P. (2009). Dependable Hydrogen and Industrial Heat Generation from the Next Generation Nuclear Plant. Proceedings of National Hydrogen Association. Columbia, SC.

Thermea Energiesysteme. (2008) High Temperature Large Scale Heat Pumps for Industrial Use. Retrieved May 9, 2013, from Everything R744: http://www.r744.com/assets/link/thermea_broschuere_short.pdf

Wongsuwan, W., Kumar, S., Neveu, P., \& Meunier, F. (2001). A Review of Chemical Heat Pump Technology and Applications. Applied Thermal Engineering, 21, 1489-1519.

Yu, Y., Zhang, P., Wu, J., \& Wang, R. (2008). Energy upgrading by solid-gas reaction heat transformer: A critical review. Renewable and Sustainable Energy Reviews, 12, 13021324 